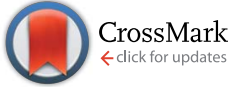

Cite this: RSC Adv., 2017, 7, 11522

Received 22nd January 2017 Accepted 8th February 2017

DOI: 10.1039/c7ra00933j

rsc.li/rsc-advances

\section{The path of mass transfer during Au thin film- assisted chemical etching by designed surface barriers}

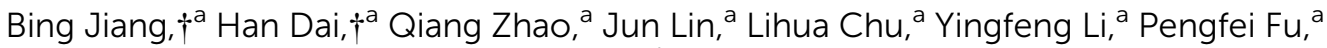 \\ Gaoxiang Wu, ${ }^{a}$ Jun $\mathrm{Ji}^{\mathrm{a}}$ and Meicheng Li ${ }^{\star a b}$
}

\begin{abstract}
The mass transfer in metal-assisted chemical etching between the interfaces has been revealed directly by an epoxy protection method. The results show that the dissolution of Si occurs in the Au film surface instead of the Au-Si interface. A mass transfer path inside the Au film is proposed, in which the Si atoms dissolve in the Au film, and then diffuse across the Au lattice, and are oxidized and etched away at the Au film/solution interface. This model is proved by the oxidation products of $\mathrm{Si}$ atoms $\left(\mathrm{SiO}_{2}\right.$ and $\left.\mathrm{SiF}_{6}{ }^{2-}\right)$ on the surface of the Au thin film. In addition, the abnormal emission of $\mathrm{H}_{2}$ at the $\mathrm{Au}-\mathrm{Si}$ interface indicates the probability of the diffusion of $\mathrm{H}$ atoms inside the Au film during the etching. This work provides a further insight into the mechanism of metal-assisted chemical etching.
\end{abstract}

\section{Introduction}

Nanostructures of silicon (Si) are the most important materials for the current functional devices, such as nanoelectronics, ${ }^{1}$ opto-electronics, ${ }^{2}$ energy conversion ${ }^{3-7}$ and storage devices, ${ }^{8}$ as well as bio- and chemical sensors. ${ }^{9,10}$ Controllable fabrication of Si nanostructures is a prerequisite for their device applications. In recent years, metal-assisted chemical etching (MacEtch), which is a facile and cost-effective method for fabricating $\mathrm{Si}$ nanostructures with size features and controlled orientation, has attracted considerable attention.

A lot of Si nanostructures have been prepared by MacEtch, such as $\mathrm{Si}$ nanowires, porous $\mathrm{Si}$ structures, and combined structures with Si micropillars and nanowires. ${ }^{11-15}$ Despite the overall etching process in which the effect of noble metal on the anode and cathode reaction are explained, the complex or even conflicted phenomena in etching process still exist. For understanding complex etching phenomena, two main mass transfer models during etching process were proposed.$^{16}$ The assumptions in the models describe the different evolution of oxidization and dissolution of $\mathrm{Si}$ atom in etching process. In Model I, it has been speculated that Si atoms are oxidized and dissolved at the interface between the noble metal and the $\mathrm{Si}$ substrate and that the reagent and byproduct diffuses along this interface. However, even though difficulties in observing in situ etching process, there are experiment results support this

${ }^{a}$ State Key Laboratory of Alternate Electrical Power System with Renewable Energy Sources, North China Electric Power University, Beijing 102206, China. E-mail: mcli@ncepu.edu.cn; Fax: +86-10-61772951

${ }^{b}$ Suzhou Institute, North China Electric Power University, Suzhou 215123, China

$\dagger$ These authors contributed equally to this work. assumption. ${ }^{17}$ Model II is another possibility concerning mass transfer, in which the $\mathrm{Si}$ atoms that contacting with a noble metal are dissolved in the noble metal and then diffuse through the noble metal to the solution where the silicon atoms are oxidized and etched away at the noble metal/solution interface. As yet, there is no direct evidence in the literature proving unambiguously which of the two diffusion processes dominates the metal-assisted chemical etching. In this paper, a series of experiments are designed to reveal the process of mass transfer during the metal-assisted chemical etching, which can be used to understanding the etching process.

\section{Experimental details}

The p-Si (100) single crystal wafers with resistivity of $\rho \sim 7-13$ $\Omega \mathrm{cm}$ were purchased from Emei Semiconductor Factory, China. Single-polished wafers were cut into $3.0 \mathrm{~cm} \times 1.0 \mathrm{~cm}$ pieces and used for the experiments. Using the $\mathrm{Al}$ foil template, the Au films with $0.5 \mathrm{~cm} \times 0.5 \mathrm{~cm}$ areas and $100 \mathrm{~nm}$ thickness were deposited on the Si substrate by the physical vapor deposition. Then, the specimens were annealed at $110^{\circ} \mathrm{C}$ for 1 hour. After that, the epoxy drops were dropped on the surface of $\mathrm{Au}$ thin film as the barrier layers, as shown in Fig. 1a and b. Fig. 1c shows an epoxy drop on the Au film surface observed by optical microscope. Finally, the Au film was used as the catalyst to etch Si nanostructures by two different etching processes. One is that putting the whole specimen into the etchant solution consisted of $\mathrm{HF}, \mathrm{H}_{2} \mathrm{O}_{2}$ and $\mathrm{H}_{2} \mathrm{O}$ for 30 s. Fig. 1d shows the picture of specimen after etching in the solution. The other one is that directly dropping one or two dips of etchant solution on the $\mathrm{Au}$ surface for $30 \mathrm{~s}$. After etching, the Au film in the specimen was cleaned by high concentration acid solution and the epoxy was 

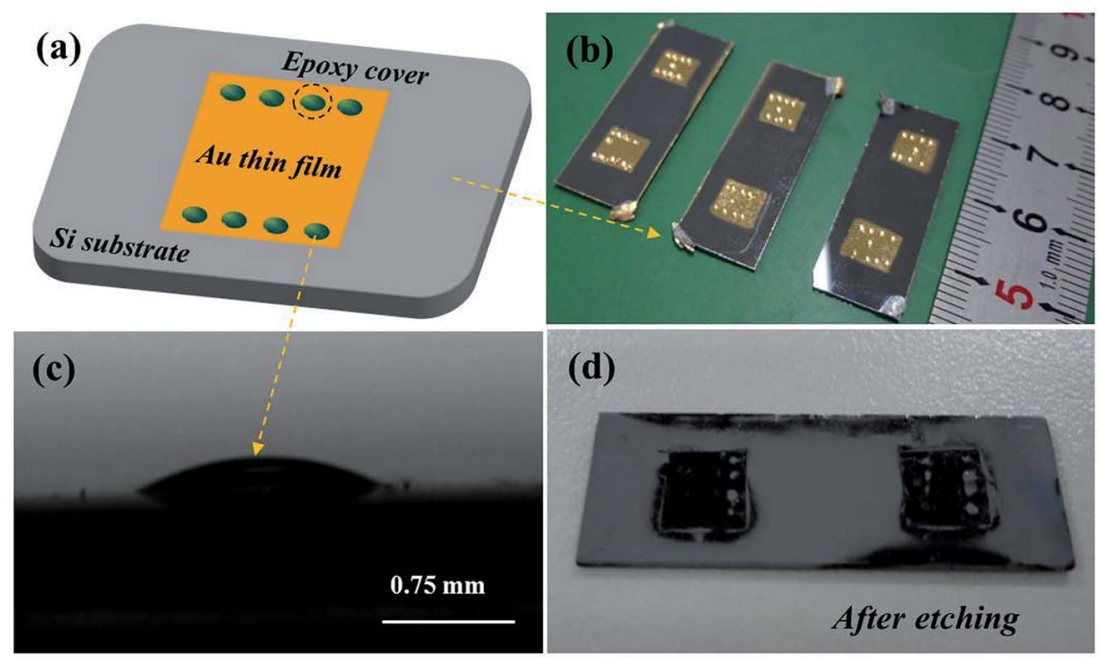

Fig. 1 The schematic image and the pictures of the epoxy drops on the specimen. (a) Schematic image of specimen (b) the photo of the epoxy drops on the square Au films; (c) the micrograph of an epoxy drop on the Au film observed by optical microscope (d) the photo of the specimen after etching in the etchant solution.

removed by acetone. The morphology of the Si nanostructures after etching was characterized by optical microscope (OM, Yongxiang corp., Model 10XB-PC), scanning electron microscope (SEM, FEI Quanta 200F) and atomic force microscope (AFM, Agilent 5500). The components of byproducts after etching reaction were characterized by X-ray photoelectron spectroscopy (XPS, VG Scientific Ltd. Model ESCALAB MK II).

\section{Results and discussion}

Obviously, the main discrepancy between Model I and Model II is the different diffusion path of Si in etching process. Therefore, the methods of hindering the diffusion path of Si can be used to reveal the mass transfer mechanism in MacEtch process. In this work, the epoxy drops were used as the barriers to explore the diffusion path of Si during the etching process.

In the first etching process, the specimen was directly put into the solution. After etching inside the solution, there are two different etching areas under Au film with and without epoxy, as shown in Fig. 1d. Fig. 2a and b show the morphology of the epoxy drop on the Au film and the Si surface after etching in the same position, which is observed by optical microscope. In Fig. $2 \mathrm{~b}$, the dark areas are the Si substrates have been etched, demonstrated by the anti-reflectance property of porous Si. Apparently, the bright area that has similar shape with the epoxy drop has been less affected by the etching solution. Through the SEM observation, Si substrate with the epoxy protection still contains the similar morphology to the original Si surface, as shown in Fig. $3 \mathrm{~b}$ and c. However, the typical porous $\mathrm{Si}$ is observed on the surface under $\mathrm{Au}$ film without epoxy, as shown in Fig. $3 \mathrm{~b}$ and d. The results show that Au film acts as a catalyst to induce the etching of Si substrate. If Model I works, Si could dissolve at the $\mathrm{Au} / \mathrm{Si}$ interface due to the diffusion of reagent and byproduct, even though the epoxy covers the $\mathrm{Au}$ film. ${ }^{16}$ In this assumption, the Si substrate under $\mathrm{Au}$ film catalyst should be also etched, even though the epoxy covers the $\mathrm{Au}$ film. However, the results show that the epoxy drops on the $\mathrm{Au}$ film actually block the etching process, so that the corresponding areas on Si substrate won't be etched, even though the Si substrate contacts directly to Au film. The results give a proof of Model II for mass transfer, in which the back bonds of the $\mathrm{Si}$ atoms at the $\mathrm{Au} / \mathrm{Si}$ interface and $\mathrm{Au}$ are broken; the free Si atoms
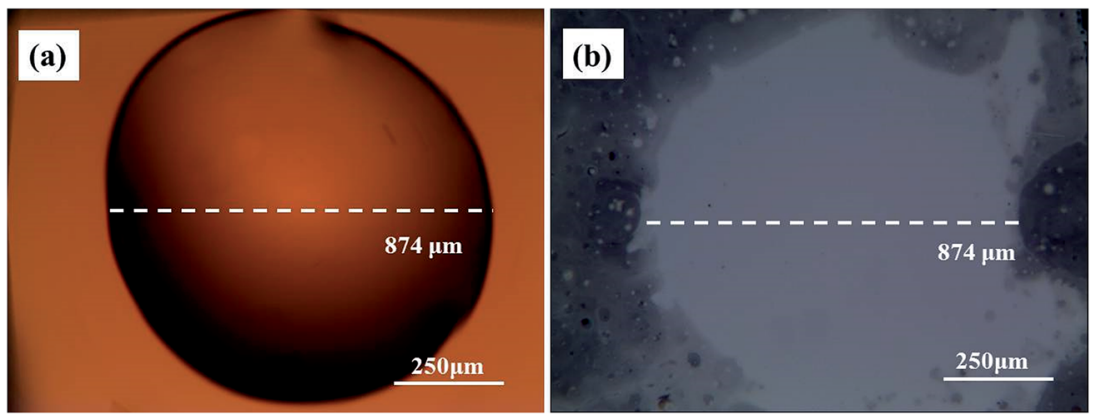

Fig. 2 The morphology of the Au film surface and Si surface before and after etching. (a) Optical microscopy image of epoxy drop on Au film before etching; (b) Si substrate after etching. 

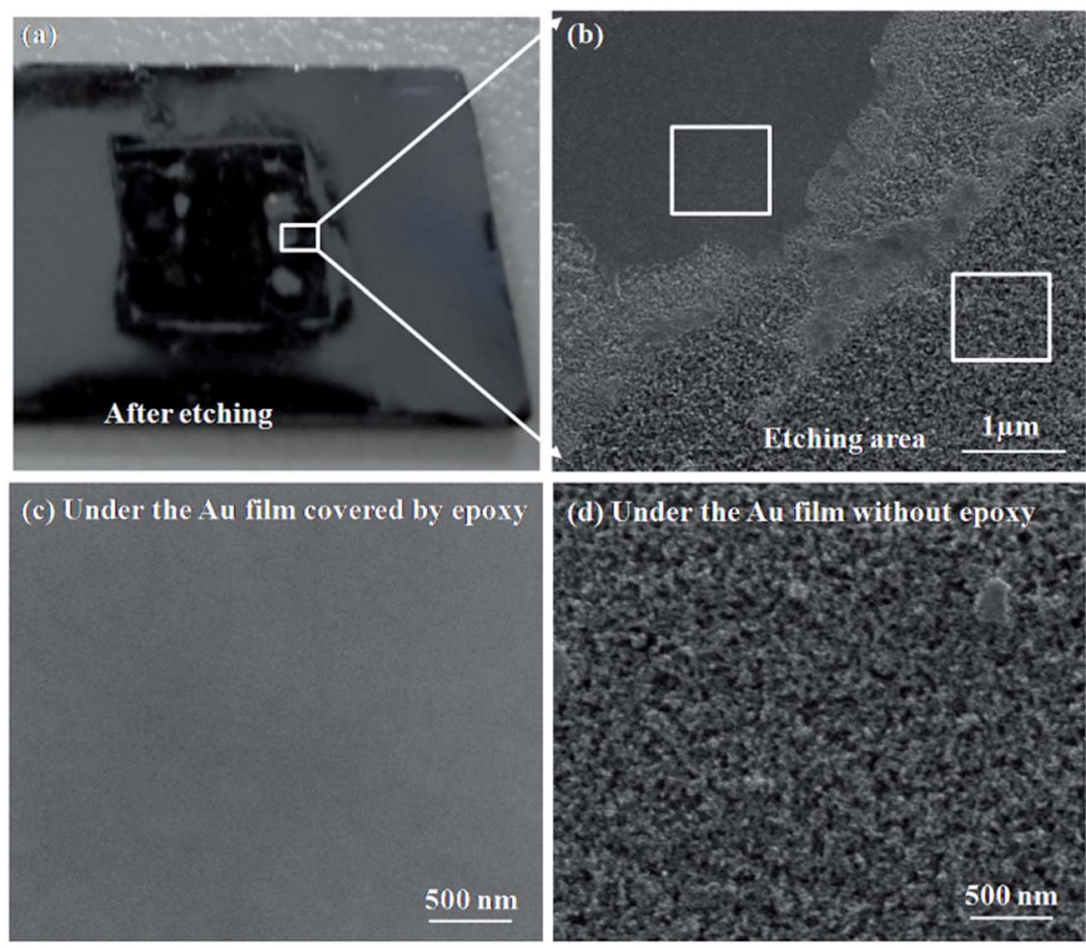

Fig. 3 Morphology on different areas with and without epoxy of the Si substrate after etching. (a) The specimen after etching; (b) the etching area on the edge of epoxy; (c) Si substrate under the Au film with epoxy; (d) Si structures under the Au film without epoxy.

are dissolved into the noble metal, diffuse through Au film, and are thermally oxidized and etched away at the Au film/solution interface. In this experiment, the epoxy drops on the Au film are as the barriers for diffusion and dissolution of $\mathrm{Si}$ atoms, resulting in Si substrate of this area cannot be etched.

In previous studies, Si substrates always are immerged into the etchant solution during most of the etching reactions. ${ }^{18-20} \mathrm{In}$ the solution, the etchant could flow to the $\mathrm{Au} / \mathrm{Si}$ interface from the out edge of Au film. In order to avoid the flowing of etchant solution, we use another special etching process, in which one or two dips of etchant solution were directly dropped on the top of Au film and no flowing to the edge of Au film. After etching about $30 \mathrm{~s}$, the following process is similar to the specimen etched inside solution. Compared with the reaction inside the solution, the similar results are achieved by etchant dropping, in which the Si substrate with the epoxy protection is not etched. The surface roughness of Si substrate before and after etching is characterized by atomic force microscope (AFM), as shown in Fig. 4. The AFM analysis shows that the roughness of Si nanostructures without epoxy is about $14.8 \mathrm{~nm}$ after etching, which is larger than that of original $\mathrm{Si}$ and the Si substrate with epoxy protection (roughness is about $1 \mathrm{~nm}$ ). Obviously, the epoxy covers efficiently hinder the etching reaction of $\mathrm{Si}$ substrate underneath it. This result shows that the Si atoms cannot directly transfer into the solution due to the Au barrier between the solution and Si substrate, which excludes the mass transfer path of Model I.

The direct contact between $\mathrm{Au}$ and $\mathrm{Si}$ leads to form $\mathrm{Au}-\mathrm{Si}$ bonds which could weaken the Si-Si bonds. In fact, the direct penetration of Si atoms through Au thin films has been reported previously. ${ }^{21}$ Thus, it is possible for $\mathrm{Si}$ atoms to diffuse through the $\mathrm{Au}$ film, then are oxidized to $\mathrm{SiO}_{2}$ and reacted with $\mathrm{HF}$ to produce $\mathrm{H}_{2} \mathrm{SiF}_{6}$ on the surface of $\mathrm{Au}$ film. To prove the assumption of Model II, the byproducts on the surface of $\mathrm{Au}$ film before and after etching are investigated through the XPS analysis. The Au film surface after etching was treated by $\mathrm{KOH}$ solution before XPS test, because the main product of $\mathrm{H}_{2} \mathrm{SiF}_{6}$ is a volatile chemical, which is hard to characterize after etching. The results show that there is no information of other elements besides $\mathrm{Au}$ before etching. While after etching, the $\mathrm{SiF}_{6}{ }^{2-}$ and $\mathrm{SiO}_{2}$ have been investigated on the top of Au thin film, as shown in Fig. 5a, b, d and e. Therefore, in our experiments $\mathrm{Si}$ atoms actually diffuse through the Au film and produce to $\mathrm{H}_{2} \mathrm{SiF}_{6}$ on the surface of $\mathrm{Au}$ film instead of the $\mathrm{Au} / \mathrm{Si}$ interface. Moreover, the peak shift of $\mathrm{Au} 4 \mathrm{f}$ has been also found and the reason will be discussed below.

During the etching process, it was found that some gases assemble on the Si substrate under the Au film and then release and damage the Au film during the etching, as shown in Fig. 6. The large holes on Au film in the Fig. 6a may be caused by the releasing of the gases during the etching. In the edge of the holes, there are some bulges on Au film, which are caused by the gas which not yet released from the $\mathrm{Au} / \mathrm{Si}$ interface, as shown in Fig. 6b. This result may be related to the reaction product of $\mathrm{H}_{2}$, which is from the $\mathrm{H}^{+}$in general cathode reaction proposed in literature. ${ }^{22,23}$ However, the transfer path of $\mathrm{H}^{+}$is not yet clear, because during the etching process in solution, the etchant may diffuse from the out edge of $\mathrm{Au}$ film to the $\mathrm{Au}-\mathrm{Si}$ interface. Therefore, the surface cracks on Au thin film are investigated by SEM, AFM and XPS respectively. The results show that there is 

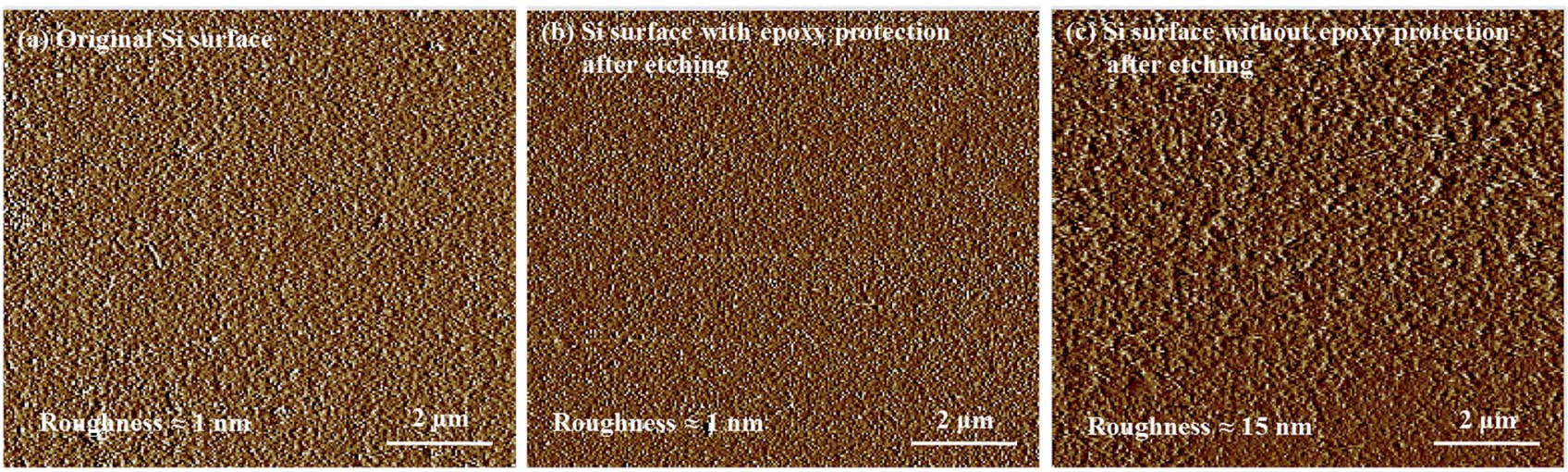

Fig. 4 AFM image of (a) original Si substrate; (b) the Si surface under the epoxy protection after etching; (c) the Si surface without the epoxy protection after etching.
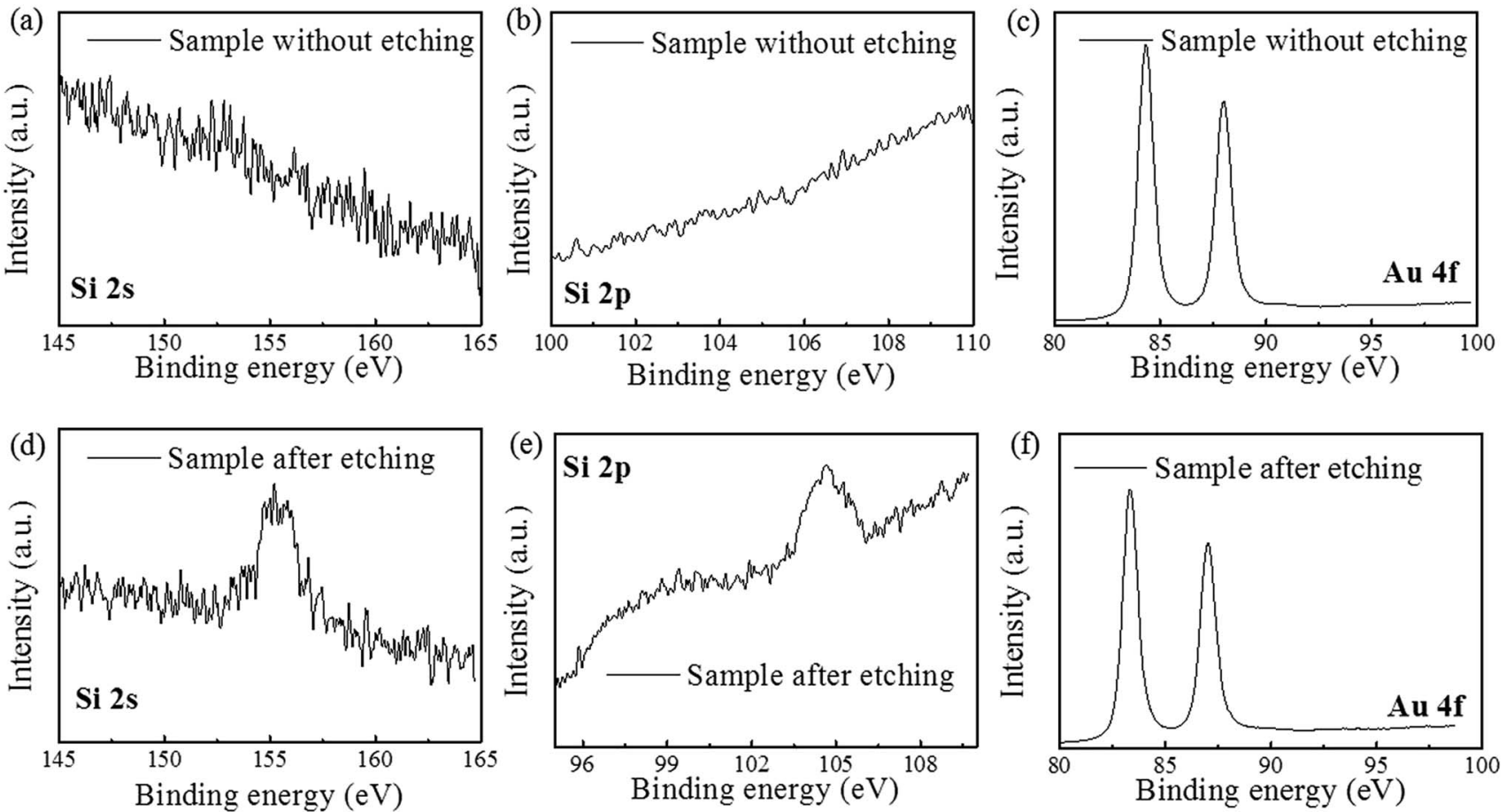

Fig. 5 XPS result on the Au film surface (a-c) before etching and (d-f) after etching. (a), (b), (d) and (e) show the change of $\mathrm{SiF}_{6}{ }^{2-}$ and $\mathrm{SiO}_{2} ;(\mathrm{c})$ and (f) show the shift of the peak of Au $4 f$.

no obvious crack on Au thin film and roughness of Au thin films is about $1 \mathrm{~nm}$ by AFM. In order to avoid missing observation of the molecular scale cracks in a larger range (about $\mathrm{mm}^{2}$ ), XPS analysis is also used to test the surface of the Au thin film. In the Fig. 5c, the only signal of Au on the surface before etching shows that the Au film has a good molecular scale density. Moreover, the shift of the peak of $\mathrm{Au} 4 \mathrm{f}$ in Fig. $5 \mathrm{f}$ attributes to the formation of the $\mathrm{Au}$ compound. Therefore, the intensely etching reaction observed in our experiments cannot be supported by the infiltration of HF through the Au thin film. Actually, the $\mathrm{H}^{+}$ in some way diffuses through the Au film and produces the $\mathrm{H}^{2}$ at the $\mathrm{Au} / \mathrm{Si}$ interface. Similar to the electrochemical penetration of $\mathrm{H}$ atoms in $\mathrm{Al}$ foil, the penetration of $\mathrm{H}$ atoms on the $\mathrm{Au}$ film in the acidic solution can be expressed below: ${ }^{24}$

$$
\begin{gathered}
\mathrm{Au}+\mathrm{H}^{+}+\mathrm{e}^{-}=\mathrm{AuH} \\
\mathrm{AuH}+\mathrm{H}_{2} \underset{\mathrm{Si} / \mathrm{Au}}{\stackrel{\mathrm{Au} / \text { solution }}{\rightleftarrows}}\left(\mathrm{H}_{2}\right) \mathrm{AuH}
\end{gathered}
$$

Moreover, the dynamic of the release of $\mathrm{H}_{2}$ in the interface of $\mathrm{Si} / \mathrm{Au}$ is complex, which is related to both the vacant left after $\mathrm{Si}$ atoms diffusion and surface barrier of reaction products $\mathrm{SiO}_{2}$ on Au surface.

Based on above results, it is found that the mass transfer in metal assisted $\mathrm{Si}$ etching process is mainly vertical to the surface in the initial period, which is similar to Model II. Fig. 7 shows the schematic diagram of the mass transfer model. The significant difference from the Model $\mathrm{I}$ is the transfer and 

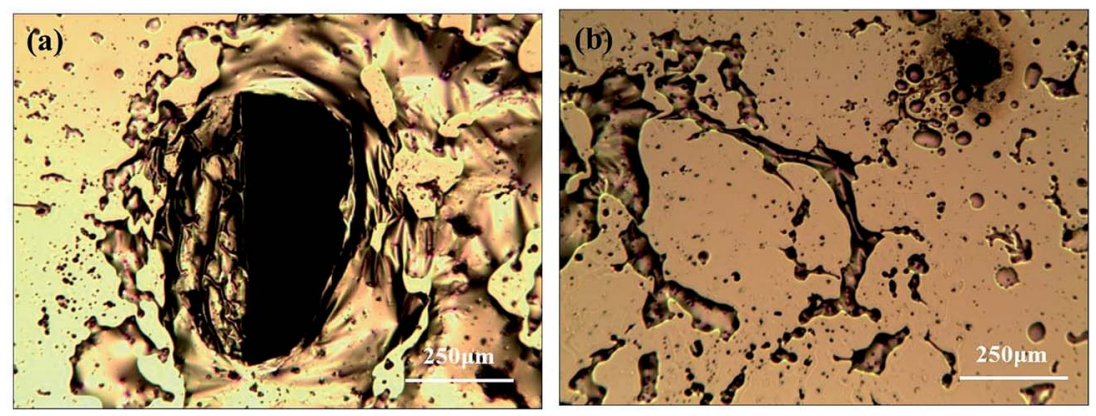

Fig. 6 Optical image of the assemble of $\mathrm{H}_{2}$ under the $\mathrm{Au}$ film and the damage of the Au film caused by the release of $\mathrm{H}_{2}$ (a) optical image in the center area of the $\mathrm{H}_{2}$ bubble; (b) optical image in marginal area.

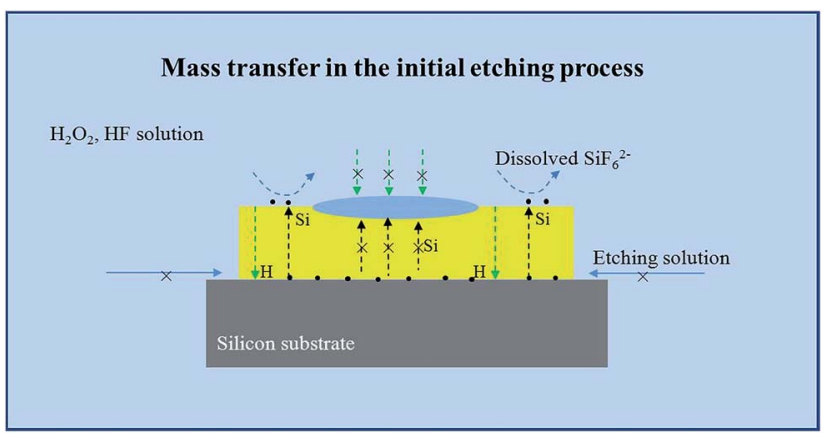

Fig. 7 Schematic image of mass transfer during the initial etching process. The reaction occurs at the interface of Au film and solution: Si atoms diffuse through the $\mathrm{Au}$ film and produce to $\mathrm{H}_{2} \mathrm{SiF}_{6}$ on the surface of Au film; $\mathrm{H}^{+}$in some way diffuses through the Au film and produces the $\mathrm{H}^{2}$ at the $\mathrm{Au} / \mathrm{Si}$ interface.

diffusion of $\mathrm{Si}$ and $\mathrm{H}$ atoms inside the $\mathrm{Au}$ film. It is worth to note that this vertical mass transfer model in only effective in the initial period of the etching process. With increase of the etching time, the morphology of $\mathrm{Au}$ thin film is broken by $\mathrm{H}_{2}$ product, which leads to the transverse transfer of the etchant solution between $\mathrm{Au} / \mathrm{Si}$ interfaces. At the moment, the vertical transfer of $\mathrm{Si}$ atoms and the transverse transfer of the etchant solution between $\mathrm{Au} / \mathrm{Si}$ interfaces occur simultaneously. The massive etchant solution can diffuse into the $\mathrm{Au} / \mathrm{Si}$ interfaces, which leads to the bad contact of $\mathrm{Au}-\mathrm{Si}$. During this etching period, the typical electrochemical reaction indicates that the transverse transfer of the etchant solution between $\mathrm{Au} / \mathrm{Si}$ interfaces could dominate the etching process.

\section{Conclusion}

In summary, a series of experiment are designed to investigate the mass transfer and etching mechanism during metalassisted etching process. For the etching process with Au film as the catalyst, the surface protect layer can hinder the diffusion path of Si atoms, which reveals the mass transfer model in MacEtch process. The results show that the intense etching reactions occur in the interface between the $\mathrm{Au}$ film and $\mathrm{Si}$ surface, which do not contact directly with the etchant solution. That is, the dominate reaction dynamics of Si etching is the diffusion of $\mathrm{Si}$ atoms through Au film, which is consistent with the Model II of mass transfer in literature. Meanwhile, we found that $\mathrm{H}$ ions transfer and diffuse in the interface between $\mathrm{Si} / \mathrm{Au}$ and produce $\mathrm{H}_{2}$, which leads to the damage of $\mathrm{Au}$ film. The results give the better understanding for mass transfer during the initial etching process. Looking forward, the epoxy protection on catalyst could be used to the more accurate morphologycontrolled fabrication of Si nanostructures.

\section{Acknowledgements}

This work is supported partially by National High-tech R\&D Program of China (863 Program, No. 2015AA034601), National Natural Science Foundation of China (Grant no. 91333122, 61204064, 51202067, 51372082, 51402106 and 11504107), PhD. Programs Foundation of Ministry of Education of China (Grant no. 20130036110012), Par-Eu Scholars Program, and the Fundamental Research Funds for the Central Universities (Grant no. 2015ZD07).

\section{References}

1 V. Schmidt, H. Riel, S. Senz, S. Karg, W. Riess and U. Gösele, Realization of a Silicon Nanowire Vertical Surround-Gate Field-Effect Transistor, Small, 2006, 2, 85-88.

2 B. Tian, X. Zheng, T. J. Kempa, Y. Fang, N. Yu, G. Yu, J. Huang and C. M. Lieber, Coaxial silicon nanowires as solar cells and nanoelectronic power sources, Nature, 2007, 449, 885-889.

3 K. Peng, A. Lu, R. Zhang and S.-T. Lee, Motility of Metal Nanoparticles in Silicon and Induced Anisotropic Silicon Etching, Adv. Funct. Mater., 2008, 18, 3026-3035.

4 Z. Huang, T. Shimizu, S. Senz, Z. Zhang, X. Zhang, W. Lee, N. Geyer and U. Gösele, Ordered Arrays of Vertically Aligned [110] Silicon Nanowires by Suppressing the Crystallographically Preferred <100> Etching Directions, Nano Lett., 2009, 9, 2519-2525.

5 F. Hui, L. Xudong, S. Shuang, X. Ying and Z. Jing, Fabrication of slantingly-aligned silicon nanowire arrays for solar cell applications, Nanotechnology, 2008, 19, 255703.

6 D. Kumar, S. K. Srivastava, P. K. Singh, M. Husain and V. Kumar, Fabrication of silicon nanowire arrays based 
solar cell with improved performance, Sol. Energy Mater. Sol. Cells, 2011, 95, 215-218.

7 F. Bai, M. Li, D. Song, H. Yu, B. Jiang and Y. Li, One-step synthesis of lightly doped porous silicon nanowires in $\mathrm{HF} /$ $\mathrm{AgNO}_{3} / \mathrm{H}_{2} \mathrm{O}_{2}$ solution at room temperature, J. Solid State Chem., 2012, 196, 596-600.

8 K. Q. Peng, J. S. Jie, W. J. Zhang and S. T. Lee, Silicon nanowires for rechargeable lithium-ion battery anodes, Appl. Phys. Lett., 2008, 93.

9 Y. Cui, Q. Wei, H. Park and C. M. Lieber, Nanowire Nanosensors for Highly Sensitive and Selective Detection of Biological and Chemical Species, Science, 2001, 293, 1289-1292.

10 F. Patolsky, G. Zheng and C. M. Lieber, Fabrication of silicon nanowire devices for ultrasensitive, label-free, real-time detection of biological and chemical species, Nat. Protoc., 2006, 1, 1711-1724.

11 F. Bai, M. Li, R. Huang, Y. Li, M. Trevor and K. P. A. Musselman, One-step template-free approach to achieve tapered silicon nanowire arrays with controllable filling ratios for solar cell applications, RSC Adv., 2014, 4, 1794-1798.

12 F. Bai, M. Li, R. Huang, D. Song, B. Jiang and Y. Li, Templatefree fabrication of silicon micropillar/nanowire composite structure by one-step etching, Nanoscale Res. Lett., 2012, 7, 1-5.

13 L. Li, Y. Liu, X. Zhao, Z. Lin and C.-P. Wong, Uniform Vertical Trench Etching on Silicon with High Aspect Ratio by MetalAssisted Chemical Etching Using Nanoporous Catalysts, ACS Appl. Mater. Interfaces, 2013, 6, 575-584.

14 S. Yae, Y. Morii, N. Fukumuro and H. Matsuda, Catalytic activity of noble metals for metal-assisted chemical etching of silicon, Nanoscale Res. Lett., 2012, 7, 352-358.

15 B. Jiang, M. Li, Y. Liang, Y. Bai, D. Song, Y. Li and J. Luo, Etching anisotropy mechanisms lead to morphologycontrolled silicon nanoporous structures by metal assisted chemical etching, Nanoscale, 2016, 8, 3085-3092.
16 Z. Huang, N. Geyer, P. Werner, J. de Boor and U. Gosele, Metal-assisted chemical etching of silicon: a review, Adv. Mater., 2011, 23, 285-308.

17 G. Liu, K. L. Young, X. Liao, M. L. Personick and C. A. Mirkin, Anisotropic Nanoparticles as Shape-Directing Catalysts for the Chemical Etching of Silicon, J. Am. Chem. Soc., 2013, 135, 12196-12199.

18 Z. Huang, X. Zhang, M. Reiche, L. Liu, W. Lee, T. Shimizu, S. Senz and U. Gösele, Extended Arrays of Vertically Aligned Sub-10 nm Diameter [100] Si Nanowires by MetalAssisted Chemical Etching, Nano Lett., 2008, 8, 3046-3051.

19 Z. Zuo, G. Cui, Y. Shi, Y. Liu and G. Ji, Gold-thicknessdependent Schottky barrier height for charge transfer in metal-assisted chemical etching of silicon, Nanoscale Res. Lett., 2013, 8, 1-7.

20 K. Peng, W. Yin, F. Hui, X. Zhong, X. Ying and Z. Jing, Uniform, axial-orientation alignment of one-dimensional single-crystal silicon nanostructure arrays, Angew. Chem., 2005, 44, 2737-2742.

21 A. Cros, J. Derrien and F. Salvan, Catalytic action of gold atoms on the oxidation of $\mathrm{Si}(111)$ surfaces, Surf. Sci. Lett., 1981, 110, A356-A357.

$22 \mathrm{X}$. Li and P. W. Bohn, Metal-assisted chemical etching in HF/ $\mathrm{H}_{2} \mathrm{O}_{2}$ produces porous silicon, Appl. Phys. Lett., 2000, 77, 2572-2574.

23 Y. Harada, X. Li, P. W. Bohn and R. G. Nuzzo, Catalytic Amplification of the Soft Lithographic Patterning of Si. Nonelectrochemical Orthogonal Fabrication of Photoluminescent Porous Si Pixel Arrays, J. Am. Chem. Soc., 2001, 123, 8709-8717.

$24 \mathrm{X}$. Wang and L. Andrews, Infrared Spectra and DFT Calculations for the Gold Hydrides $\mathrm{AuH},\left(\mathrm{H}_{2}\right) \mathrm{AuH}$, and the $\mathrm{AuH}_{3}$ Transition State Stabilized in $\left(\mathrm{H}_{2}\right) \mathrm{AuH}_{3}$, J. Phys. Chem. A, 2002, 106, 3744-3748. 